\title{
Induction of Innate Immune Genes in Brain Create the Neurobiology of Addiction
}

\author{
FT Crews ${ }^{1}$, Jian Zou ${ }^{2}$, and Liya Qin ${ }^{3}$ \\ ${ }^{1}$ Bowles Center for Alcohol Studies, Department of Pharmacology and Psychiatry, School of \\ Medicine, The University of North Carolina at Chapel Hill, Thurston-Bowles Building, CB 7178, \\ Chapel Hill, NC 27599-7178 \\ ${ }^{2}$ Bowles Center for Alcohol Studies, Department of Pharmacology and Psychiatry, School of \\ Medicine, The University of North Carolina at Chapel Hill, Thurston-Bowles Building, CB 7178, \\ Chapel Hill, NC 27599-7178 \\ ${ }^{3}$ Bowles Center for Alcohol Studies, Department of Pharmacology and Psychiatry, School of \\ Medicine, The University of North Carolina at Chapel Hill, Thurston-Bowles Building, CB 7178, \\ Chapel Hill, NC 27599-7178
}

\begin{abstract}
Addiction occurs through repeated abuse of drugs that progressively reduce behavioral control and cognitive flexibility while increasing limbic negative emotion. Recent discoveries indicate neuroimmune signaling underlies addiction and co-morbid depression. Low threshold microglia undergo progressive stages of innate immune activation involving astrocytes and neurons with repeated drug abuse, stress, and/or cell damage signals. Increased brain NF- $\kappa B$ transcription of proinflammatory chemokines, cytokines, oxidases, proteases, TLR and other genes create loops amplifying NF- $\mathrm{KB}$ transcription and innate immune target gene expression. Human post-mortem alcoholic brain has increased NF- $\mathrm{KB}$ and NF- $\mathrm{\kappa B}$ target gene message, increased microglial markers and chemokine-MCP1. Polymorphisms of human NF- $\mathrm{kB} 1$ and other innate immune genes contribute to genetic risk for alcoholism. Animal transgenic and genetic studies link NF- $\mathrm{KB}$ innate immune gene expression to alcohol drinking. Human drug addicts show deficits in behavioral flexibility modeled pre-clinically using reversal learning. Binge alcohol, chronic cocaine, and lesions link addiction neurobiology to frontal cortex, neuroimmune signaling and loss of behavioral flexibility. Addiction also involves increasing limbic negative emotion and depression-like behavior that is reflected in hippocampal neurogenesis. Innate immune activation parallels loss of neurogenesis and increased depression-like behavior. Protection against loss of neurogenesis and negative affect by anti-oxidant, anti-inflammatory, anti-depressant, opiate antagonist and abstinence from ethanol dependence link limbic affect to changes in innate immune signaling. The hypothesis that innate immune gene induction underlies addiction and affective disorders creates new targets for therapy.
\end{abstract}

(C) 2011 Elsevier Inc. All rights reserved.

Person to whom correspondence should be sent: Dr. Fulton T. Crews, Ph.D., Bowles Center for Alcohol Studies, The University of North Carolina at Chapel Hill, The School of Medicine, CB \#7178, 1021 Thurston-Bowles Building, Chapel Hill, NC 27599-7178, fulton_crews@med.unc.edu, Phone: 919-966-5678, Fax: 919-966-5679.

Publisher's Disclaimer: This is a PDF file of an unedited manuscript that has been accepted for publication. As a service to our customers we are providing this early version of the manuscript. The manuscript will undergo copyediting, typesetting, and review of the resulting proof before it is published in its final citable form. Please note that during the production process errors may be discovered which could affect the content, and all legal disclaimers that apply to the journal pertain. 


\section{Keywords}

Addiction; Drug Abuse; Alcoholism; cytokines; chemokines; microglia; depression; reversal learning; frontal cortex; neurogenesis

\section{Introduction: Severe addiction is the result of loss of behavioral control and increased limbic drive}

Chronic use of alcohol stimulants and/or opiates lead to progressive changes in the brain and behavior, often leading good, smart and sane people to do bad, stupid and crazy things that hurt themselves and others. The continued and often escalating horrific, unpleasant, awful events associated with increasing drug use resulting in addiction are well known. Medical emergencies due to accidents, drug overdoses, violent desperate, impulsive illegal behavior, physical injuries criminal justice problems (Li 2008; Gilson 2010) and other negative consequences associate with drug addiction (Hingson et al. 2009; Mendelson et al. 1986). Alcohol or opiate dependence was first defined by neurological and physiological withdrawal symptoms including hyperexcitability, fever, anxiety and feelings of sickness. However, modern medicine focuses psychological dependence that causes loss of behavioral control (Kalivas and O'Brien 2008; Koob and Volkow 2010). Addiction can be defined as a primary, chronic, neurobiological disease, with genetic, psychosocial, and environmental factors influencing its development and manifestations. It is characterized by behaviors that include impaired control over drug use, compulsive use, continued use despite harm, and craving (Ries et al. 2009; Volkow et al. 2011). Substance Dependence, a Psychiatric diagnosis is defined as "repeated use of alcohol or other drugs despite problems related to use of the substance (O'Brien 2008). Critical to these medical diagnoses of severe addiction is the continued use of drugs despite the harm to the individual, family and community due to the loss of ability to alter behavior in spite of problems. This review will describe changes in the neurobiology of the brain related to severe addiction.

\section{Addiction involves progressive loss of frontal cortical behavioral control and increasing limbic temporal lobe negative feelings}

The loss of behavioral control that underlies addiction has at least 2 components, decreased frontal cortical regulation of attention and cognitive flexibility and increased limbic fearnegative feelings (Fig. 1). The frontal lobes of brain are involved in decision making and other executive functions such as motivation, planning, goal setting and inhibition of impulses. Frontal lobe functions also predict future consequences, choose between good and bad actions (or better and best), override and suppress unacceptable social responses, and determine similarities and differences between things or events. The frontal lobes also play an important part in retaining long term emotional memories and adjusting emotions to fit socially acceptable norms important for individual integration into society. Frontal behavioral control mechanisms block impulsive mistakes and predict future rewards (Schoenbaum and Shaham 2008). Loss of these functions is a key element of the neurobiology of addiction and substance dependence (Fig. 1).

The limbic system supports a variety of functions particularly emotion, fear or elation, needs and urgency, long term memory, and olfaction. Addiction induced negative affect, mood and fear are associated with amygdale and hippocampus human temporal lobe structures (Fig. 1). Limbic urgency helps drive impulsive behaviors (Crews and Boettiger 2009). Across drugs of addition, the progression from abuse to addiction involves increasing drug wanting, negative emotional urgency and decreasing behavioral control (Jentsch and Taylor 1999; 
Robinson and Berridge 2003). Thus, the neurobiology of addiction involves dysfunctional frontal cortex behavioral control as well as exaggerated limbic urgency (Fig. 1). This review will present the hypothesis that innate immune gene induction in frontal cortex blunts behavioral control, whereas it amplifies limbic negative affect and bad feelings.

\section{Microglia and monocytes sense drug abuse and stress}

Neuroimmune signaling contributes to enteric, sensory, endocrine hypothalamic-adrenal (HPA) responses to external and internal environmental factors. Monocytes and brain microglia, are sensitive key cells involved in innate immune signaling. Neuroimmune signaling through microglia and other monocyte-like cells integrates sensory and endocrine enteric responses with brain. Microglia are unique monocyte-macrophage-like cells that share multiple stages of activation reflected morphologically and in gene expression (Hingson et al. 2009; Graeber 2010). Microglia are formed embryonically and migrate to fetal brain early in development creating a unique self-renewing monocyte-like cell that is maintained by self-renewal. Microglia and vascular monocyte-macrophages are the primary innate immune cells in brain (Ransohoff and Cardona 2010). Healthy brain contains ramified "resting" microglia known to survey brain and regulate synapses (Graeber 2010). Microglia have a low threshold of activation with initial states secreting signaling molecules, increasing expression of Major Histocompatibility Complex (MHC) proteins and Toll-like receptor proteins (TLR), key proteins involved in innate immune amplification. Morphological activation states show cellular enlargement, increased cell matrix and adhesion protein expression and progressive induction of other specific genes. Efforts to establish subtypes of microglia have designated M1 and M2 states as proinflammatory and trophic respectively, although additional subtypes continually emerge (Colton and Wilcock 2010). Activated enlarged morphology is often associated with secretion of chemokines regulating cellular movement, particularly to sites of tissue damage, that progress to proinflammatory-oxidative activation that includes protease secretion. Highly activated microglia progress to mitosis, proliferation and phagocyte oxidative bursts that oxidize and engulf waste (Graeber 2010). "Amoeboid" phagocytic rounded macrophage-like cell morphology is common in neurodegenerative diseases and senescence (Colton and Wilcock 2010). Microglia can also initiate trophic and other signals needed for healing (Crews et al. 2006). Microglia are important components of brain that regulate brain function in complex ways not fully understood. Emerging studies suggest brain suppress microglial activation promoting a trophic "resting" state (Liu et al.). Stress, ethanol, other addictive drugs as well as sensory and hormonal signals activate monocytes and microglia. Cycles of stimuli lead to microglial adaptive conditioning (Shpargel et al. 2008). Interestingly, microglial dysfunction has been discovered to contribute to obsessive-compulsive behaviors (Greer and Capecchi 2002), consistent with microglia contributing to the neurobiology of addiction. Thus, microglia are sensitive to addictive drugs and stress, that lead to progressive adaptation that could alter neurobiology and behavior through innate immune gene induction.

\section{Stress and drug abuse promote addiction and NF-kB Transcription of Innate Immune Genes}

Stress, ethanol, other addictive drugs, as well as sensory and hormonal signals, activate an oxidation sensitive transcription factor, NF- $\mathrm{BB}$ (nuclear factor kappa-light-chain-enhancer of activated B cells), that is highly expressed in monocytes and microglia. Monocytes and microglia express high levels of the transcription factor NF- $\mathrm{kB}$ as well as low levels of innate immune genes under normal conditions. Although NF- $\kappa \mathrm{B}$ is found in most cells, it is the key transcription factor involved in induction of innate immune genes in microglia and other monocyte-like cells. Stimuli such as stress, cytokines, oxidative free radicals, ultraviolet irradiation, bacterial or viral antigens, and many other signaling molecules 
increase NF- $\mathrm{kB}-\mathrm{DNA}$ binding and transcription of many genes particularly chemokines, cytokines, oxidases and proteases (Fig. 2). We find that ethanol increases NF- $\kappa B-D N A$ binding in brain in-vivo (Crews et al. 2006) or in-vitro in hippocampal-entorhinal cortex (HEC) brain slice cultures (Zou and Crews 2006). Our studies and others indicate that ethanol increases transcription of NF- $\kappa \mathrm{B}$ target genes including the chemokine MCP-1 (CCL2), the proinflammatory cytokines, TNFa, IL-1 $\beta$, and IL6, the proinflammatory oxidases, iNOS (Zou and Crews 2010), COX (Knapp and Crews 1999), NOX (Qin et al. 2008) and proteases TACE and tPA (Zou and Crews 2010) (Fig. 2). Similarly stress increases brain NF- $\mathrm{KB}$ activation (Madrigal et al. 2001), cytokines, prostaglandin E2 and COX-2 levels (Madrigal et al. 2003) in part due to reversal of acute glucocorticoid antiinflammatory responses to pro-inflammatory NF- $\kappa$ B activation in frontal cortex (Munhoz et al. 2010). Stress and drug abuse cycles promote addiction and elevate glucocorticoids (Armario 2010), likely contributing to activation of brain NF- $\mathrm{kB}$ transcription of innate immune genes. Methamphetamine shows similar persistent innate immune activation to ethanol in mice and humans (Loftis et al. 2010). Thus, the synergy of stress-drug abuse cycles leading to progressive loss of behavioral control and addiction are consistent with persistent, progressive brain innate immune gene induction.

\section{Loops amplify NF-kB innate immune gene induction by paracrine and autocrine processes}

Activation of the NF- $\kappa$ B spreads through positive loops (Fig. 2) increasing activation within and across glia and neurons (Zou and Crews 2010). Autocrine signaling involves secretion of signaling molecules that act on the same cells receptors to amplify activation of that cell, whereas paracrine signaling involves release of signals that activate cells nearby spreading the signal across cells. For example, reactive oxygen species (ROS) can increase NF- $\kappa B$ transcription of TNFa and TACE, the TNFa activating protease, as well as the TNFR1 receptor. Released TNFa stimulates NF- $\mathrm{\kappa B}$ transcription through TNFR1 amplifying the signal in that cell and adjacent cells promoting TNFa induction (Fig. 2). Stress and drugs acutely signal through brain NF- $\kappa$ B. For example, restraint stress in rats induces brain NF$\kappa \mathrm{B}$ target genes TACE and TNFa mRNA within 30 minutes, and free mature brain TNFa within 1 hour (Madrigal et al. 2002). Similarly an acute dose of ethanol activates NF- $\kappa B$ in brain within 30 minutes (Ward et al. 1996). Although NF- $\mathrm{BB}$ is expressed in most cells, in brain NF- $\kappa B$ is transcriptionally active primarily in glia (Mao et al. 2009), although, confusion regarding neuronal NF- $\mathrm{kB}$ is commonly found in the literature (Massa et al. 2006). Activation of NF- $\mathrm{KB}$ acutely leads to paracrine and autocrine amplification during repeated drug abuse and/or stressful events that create loops of NF- $\mathrm{\kappa B}$ activation amplifying innate immune gene induction (Fig. 2). The loops of NF- $\mathrm{\kappa B}$ activation lead to persistent increases in oxidative free radicals from oxidases, increased TLR expression with increased formation of endogenous TRL agonists, and chemokine-cytokine receptor upregulation (Qin et al. 2008; Zou and Crews 2010). Ethanol and stress activate microglia to secrete NF- $\kappa B$ target genes leading to mild activated morphology with repeated cycles progressively increasing innate immune gene induction. Maximally activated phagocytic oxidative burst macrophage-like microglial activation occurs with severe neurodegeneration, but is rare in addiction without severe degeneration (He and Crews 2008; Qin et al. 2008). These studies indicate that repeated drug abuse and stress lead to loops of NF- $\kappa B$ transcription of innate immune genes that mimic the progressive and persistent changes in behavior associated with the transition from drug experimentation to addiction.

\section{Astrocytes and microglia are activated in addiction}

A number of studies suggest astrocytes and microglia are activated in addiction. Using both in vitro and in vivo models through a series of elegant studies Guerri's laboratory has clearly 
established that chronic ethanol treatment induces astroglial activation and astrogliosis in brain as indicated by marked upregulation of GFAP immunoreactivity within hypertrophic astrocytes, (Wilhelmsson et al. 2006; Chvatal et al. 2007; Gomez-Pinedo et al. 2008). TLR are pattern recognition receptors that activate NF- $\kappa B$ transcription. TLR and interleukin-1 receptors are expressed on microglia and other cells during innate immune activation contributing to amplification of signaling. Recently TLR4 was discovered to contribute to persistent innate immune gene induction and neurodegeneration by ethanol (AlfonsoLoeches et al. 2010). Guerri's studies indicate that chronic ethanol upregulation and activation of TLR4-MyD88-glial NF- $\mathrm{kB}$ signaling contributes to alcohol induced neurodegeneration. Acute alcohol activates TLR4 signaling to NF- $\mathrm{\kappa B}$ as well as increasing expression of TLR4 (Alfonso-Loeches et al. 2010). These studies are consistent with ethanol induction of innate immune genes altering behavior and causing neurodegeneration related to addiction. Indomethacin, an anti-inflammatory drug, reduces chronic ethanol induction of brain innate immune genes, particularly in astrocytes, as well as neuronal markers of cell death and addiction-like behavioral dysfunction (Pascual et al. 2007) consistent with innate immune gene induction driving the neurobiology of addiction. Innate immune activation from oxidized phospholipids (Yang et al. 2010), and/or release of damage associated molecular pattern (DAMP) danger sensing molecules, such as high-mobility group box 1 (HMGB1) (Garg et al. 2010), that activate TLR and other signals are likely contributors to innate immune gene induction (Huang et al. 2010)(Fig. 2). Although loops of NF- $\kappa B$ activation are best established in models of alcoholism, all addictive drugs activate NF- $\kappa \mathrm{B}$ transcription with the development of addiction (Russo et al. 2009; Loftis et al. 2010). These studies support innate immune gene induction in glia as important contributors to the neurobiology of addiction.

\section{Innate immune molecules mimic stress and drug induced addiction-like behavior}

Anxiety and the bad feelings of negative affect are associated with increased drug craving as a key component of addiction (Breese et al. 2005; Koob and Volkow 2010). Breese' laboratory models addiction with repeated cycles of ethanol consumption and/or stress that progressively amplify anxiety and negative affect consistent with the cycles of stress and drug abuse known to promote addiction. Interestingly, brain injections of innate immune inducing molecules, e.g. the chemokine MCP-1, the cytokine TNFa, or the TLR4 agonist, lipopolysaccaride an innate immune inducer, progressively increase addiction-like anxiety substituting for an episode of stress or drug abuse (Breese et al. 2008). Cycles of stress and/ or drug abuse cause progressive addiction-like anxiety and are known to induce innate immune genes in brain. The discovery that innate immune molecules injected into brain substitute for stress and/or drug abuse cycles promoting addiction-like anxiety, supports the role innate immune genes in driving the neurocircuitry and neurobiology that result in addiction-like behavior.

\section{Naltrexone, an opiate antagonist used to treat addiction, blunts innate immune induction}

Opiates are known to be addicting drugs and have endogenous opiate receptors that contribute to the neurobiology of addiction (Koob and Volkow 2010). Opiate antagonists are used to treat both alcohol and opiate addiction. Interestingly, opiate antagonists block innate immune gene induction through a different novel mechanism that might contribute to the reversal of addiction-like behavior. LPS, endotoxin, induces large innate immune responses that are blocked by opiate antagonists (Liu et al. 2000) and protect dopamine neurons through inhibition of microglial innate immune activation and reduced NOX formation of 
ROS (Liu et al. 2000; Qin et al. 2005), independent of their opiate antagonist actions. Other studies find opiate antagonists block TLR4 activation of innate immune transcription, a site of action in innate immune loops (Fig. 2) (Gerald Frank 2011; Hutchinson 2011). Thus, opiate antagonist addiction therapy may be related to inhibition of innate immune responses.

\section{Innate immune genes are increased in addicted brain}

Insight into the neurobiology of addiction can be gained from studies of post-mortem human brain. We found monocyte chemoattractant protein 1 (MCP-1, CCL2), a key innate immune chemokine, increased several fold in multiple regions of post-mortem alcoholic brain compared to age matched moderate drinking controls (Fig. 3) (He and Crews 2008). MCP-1 protein levels from alcoholic and control human brains indicated increased MCP-1 in ventral tegmental area (VTA), substantia nigra (SN), hippocampus and amygdala of alcoholic brains. We also found increased levels of microglial markers across alcoholic brain (He and Crews 2008). Chronic alcohol treatment of mice causes a similar persistent increase in brain MCP-1 (Fig. 3) (Qin et al. 2008). Interestingly, ethanol treatment of rat hippocampal brain slice cultures also increase MCP-1 and other innate immune genes (Fig. 3) (Zou and Crews 2010). These studies indicate that ethanol induces MCP-1 in rats and mice creating neurobiological changes found in human addicted brain (Fig. 3). Similarly, human methamphetamine addicts and mice treated with methamphetamine show persistent increases in innate immune proteins (Loftis et al. 2010). Increased protein levels are also reflected by increased mRNA. Gene arrays following mRNA expression in post-mortem human alcoholic brain find increased NF- $\mathrm{kB}$ and target gene expression. Okvist (2007) found chronic alcoholic brain to contain increased NF- $\mathrm{kB}$ nuclear binding p50 subunits with $479 \mathrm{NF}-\mathrm{\kappa B}$ target genes upregulated in the frontal cortex. Another post-mortem alcoholic human gene expression analysis (Liu et al. 2006) found increases in innate immune cell adhesion and extracellular membrane (ECM) components. Thus, studies of post-mortem human alcoholic brain are consistent with increased innate immune gene expression in addicted brain.

\section{Polymorphisms of innate immune genes and genetic risk of addiction}

Genetics contribute to risk of addiction with alcoholism being the most studied and experimentally established addiction with a significant genetic risk. Genes explain about $50 \%$ of the risk of alcohol addiction (Schuckit 2009). Interestingly, polymorphisms of Cyp2E1, an enzyme that metabolizes ethanol is associated with risk for alcoholism (Webb et al. 2010). In vivo, Cyp2E1 is highly expressed in monocyte-like cells where ethanol is immediately sensed through osmotic and Cyp2E1 metabolism. Cyp2E1 metabolism of ethanol increases ROS that activate proinflammatory NF- $\kappa$ B responses (Cao et al. 2005) (Fig. 2). Other human studies have found a direct link of NF- $\mathrm{BB}$ p50 to alcohol dependence (Flatscher-Bader et al. 2005; Okvist et al. 2007; Taylor et al. 2008). Polymorphisms in the precursor gene (NF- $\kappa \mathrm{B} 1)$ of the NF- $\mathrm{kB}$ p50 subunit associate with risk for alcoholism (Taylor et al. 2008). Alleles of TNFa that increase expression have been linked to alcoholism and alcoholic liver disease (Pastor et al. 2000; Powell et al. 2000; Pastor et al. 2005). Alleles of IL-10 have also been linked to alcoholism (Pastor et al. 2000). Interestingly, in both cases alleles associated with alcoholism increase pro-inflammatory responses, e.g. alleles associated with alcoholism increase pro-inflammatory cytokine TNFa and decrease anti-inflammatory IL-10 secretion. Similarly polymorphisms, to the Interleukin-1 receptor antagonist and multiple other alleles of the IL-1 gene complex are associated with risk for alcoholism (Saiz et al. 2009). Thus, gene polymorphisms that alter innate immune NF- $\kappa \mathrm{B}$ and NF- $\kappa \mathrm{B}$ target gene expression are associated with genetic risk for human alcoholism consistent with increased brain innate immune gene expression contributing to the neurobiology of addiction. 


\section{Innate immune gene expression in brain changes behavior}

Innate immune gene expression is known to alter behavior. The most serious side effect of treatment of cancer patients with proinflammatory interferon and interleukin is severe depression that must be treated with antidepressants. Multiple other studies have linked negative affect and depression to innate immune activation (Kelley 2011). Bacterial endotoxin (LPS) an effective inducer of innate immune genes causes sickness behavior and negative affect across multiple species. In rodents, models of depression-like behavior are linked to innate immune activation and in healthy humans LPS infusions reduce reward responses and increase depressed mood (Eisenberger et al. 2010). Increased negative affect is an important component of the neurobiology of addiction (Koob and Volkow 2010).

Drug consumption is also linked to innate immune gene expression. Addictionlike drinking behavior in rats and mice associates with increased NF- $\mathrm{\kappa B}$, its regulatory proteins and innate immune genes (Mulligan et al. 2006). Interestingly, microglobulin ( $\beta 2 \mathrm{M})$ an NF- $\kappa \mathrm{B}$ target gene involved in microglial MHC immune signaling (Pahl 1999) shows the largest increase in high alcohol preferring brain transcriptomes (Mulligan et al. 2006). Innate immune gene induction in multiple mouse studies finds induction suppression through transgenic knock outs associates with increased drinking or decreased drinking respectively across strains of mice. These studies further support the role of these genes in regulating excessive addiction like drug consumption (Blednov et al. 2005; Blednov 2010). A single injection of LPS is able to produce a long-lasting increase in alcohol consumption (Blednov 2011) that corresponds to persistent increases in brain innate immune gene expression (Qin et al. 2007). These findings are consistent with innate immune gene expression driving addiction like behavior, both excessive consumption and the negative-affect, anxiety and depression-like behaviors of addiction.

\section{Innate immune genes increase negative affect and reduce neurogenesis. creating the neurobiology of addiction}

Emotion or affect have an impact on health with positive affect or happiness associating with health and negative affect, bad feeling with illness. Psychiatric affective disorders cover a range of negative affect elements including anger, anxiety, melancholia, depression, major depressive disorder and substance use disorder. Drug addiction cues include a visceral emotional "gut" reaction, often one of uneasiness until the habit is satisfied. A variety of studies suggest that the extended amygdale, a neuroanatomic circuit including the amygdale, hippocampus, bed nucleus of the stria terminalis and the nucleus accumbens integrate brain arousal-stress systems producing negative emotional states that promote the development of addiction (Koob and Volkow 2010). Mood and negative affect are reflected in the comorbidity of addiction and depression. About half of individuals with a lifetime history of alcoholism also have depression (Miller et al. 1996; Schuckit et al. 1997) and reversal of depression and alcohol dependence are linked (Mueller et al. 1994; Greenfield et al. 1998). Progressive drug-induced negative affect and depression-like behaviors are important components of addiction (Koob and Volkow 2010). The overlapping findings of increased innate immune gene expression in addiction and depression are consistent with a common molecular mechanism of addiction induced depression and endogenous depression.

A significant body of evidence supports the hypothesis that innate immune gene induction in brain causes negative affect and depression-like behavior (Raison et al. 2009). Patients with major depression have increased blood proinflammatory markers and antidepressant therapy is associated with decreases in markers. In addition to increased innate immune gene expression, human depression involves structural changes in hippocampus with multiple studies finding hippocampal volume is decreased in patients with depression (Videbech and 
Ravnkilde 2004). Other studies have associated loss of hippocampal neurogenesis, the formation of new neurons, with depression and hippocampal shrinkage. Interestingly, antidepressants increase hippocampal neurogenesis in models of depression and increase humans hippocampal volume during reversal of depression (Dranovsky and Hen 2006). Stress, multiple addictive drugs, innate immune genes and other factors that precipitate depression, reduce hippocampal neurogenesis (Tanapat et al. 2001; Malberg and Duman 2003; Gregus et al. 2005). Factors that reduce neurogenesis increase depression-like behavior (Johnson et al. 2006). Activation of NF- $\mathrm{\kappa B}$ is necessary for stress induced inhibition of neurogenesis and induction of depression-like behavior (Koo and Duman 2008) as well as social defeat models of depression (Christoffel et al. 2011). Further, antidepressant efficacy in rodent behavioral models requires hippocampal neurogenesis (Santarelli et al. 2003). In animal studies, endotoxin induced increases in innate immune genes reduce neurogenesis and increase depression-like behavior (Kelley 2011). TLRs are necessary components of both ethanol neurotoxicity (Alfonso-Loeches et al. 2010) and innate immune induced depressive behavior and reduction of neurogenesis (Kelley 2011). TLR, glutamate hyperexcitability and endogenous TLR agonists lead to persistent increases in brain hyperexcitability (Maroso et al. 2010). We have found that chronic ethanol increases brain innate immune genes, reduces brain neurogenesis and increases depressionlike behavior (Stevenson et al. 2009) (Fig. 4.) Ethanol induced loss of neurogenesis paralleled the onset of depression-like behavior with both reversed by anti-depressant treatment (Stevenson et al. 2009). Similarly stress induced IL-1 $\beta$ reduces neurogenesis causing depression like behavior (Koo and Duman 2008). Thus, neurogenesis reflects mood, with reduced neurogenesis associated with innate immune gene induction, drug induced negative affect and depression-like behavior. Interestingly, recovery from alcoholism is associated with improved mood and cognition, human brain enlargement and increased neurogenesis (Crews and Nixon 2009). Overall findings suggest adult hippocampal stem cells and neurogenesis provide an index of mood and negative affect that allow molecular studies on regulation of mood, both negative and positive (Crews and Nixon 2003; Koo et al. 2011) (Fig.4). These findings are consistent with drug induced depression sharing common mechanisms with endogenous depression as well as the negative affect of substance use disorder, e. g. addiction.

\section{Frontal cortical hyperexcitability, a key element of the neurobiology of addiction}

The frontal cortex is involved in attention, rule setting, decisions and behavioral control. It connects to multiple brain regions through excitatory glutamatergic neurons. Reciprocal connections to thalamus and limbic regions involve focal excitation that is disrupted by innate immune gene induction. In astrocytes, activation of NF- $\kappa \mathrm{B}$ increasing expression of proinflammatory innate immune genes (Zou and Crews 2006; Pascual et al. 2007; Zou and Crews 2010) and reduces astrocyte glutamate transport (Zou and Crews 2005) causing an increase in extracellular glutamate increasing neuron excitiation and excitotoxicity (Zou and Crews 2006). Innate immune induced hyperexcitability due to loss of cortical glutamate transporters inactivates the frontal lobes contributing to the neurobiology of addiction (Crews et al. 2006). Other studies have indicated genetic factors linked to a hyperglutamate state to alcoholism (Spinagel, 2005) and ethanol induced NF- $\mathrm{kB}$ activation to increased extracellular glutamate (Ward et al. 2009). Innate immune gene induction causes hyperexcitability in the spinal cord related to neuropathic pain (Graeber 2010) and in the hippocampus related to seizures (Maroso et al. 2010). Hyperexcitability in the frontal cortex results in loss of cognitive flexibility creating addiction-like behavior (Gruber 2010). Kalivas' laboratory in elegant studies have established that cocaine and stimulant addiction are related to hyperglutamate states due to alterations in the cortical glutamate transporters, 
(Reissner and Kalivas 2010). These studies and others have suggested that anti-oxidants and other drugs that block innate immune gene cascades may provide new therapies for addiction.

\section{Behavioral inflexibility and bad decisions due to innate immune gene induction}

Frontal cortical dysfunction is often investigated using reversal learning tasks. In reversal learning, expected outcomes are wrong requiring flexible behavior in response to outcomes that do not match those predicted by the preceding cues (Stalnaker et al. 2009). Reversal learning tasks in behavioral studies mimic the inability of drug addicted individuals to learn new healthy behaviors, when alcohol and other drugs have established strong associations. A frontal cortical signal is needed to indicate the value of decisions and is needed when new learning and/or behavior is necessary. We found that models of binge drinking induce persistent deficits in reversal learning in rats (Obernier et al. 2002) and in adult mice following a model of adolescent binge drinking (Coleman 2010). Other studies have found rats with previous experience either with self-administration of cocaine or with passive cocaine injections, are abnormally slow to learn reversals, even though they learn initial contingencies at a normal rate (Schoenbaum et al. 2004; Calu et al. 2007). Lesions of the frontal cortex cause reversal learning deficits in tasks similar to chronic drug abuse induced deficits (Schoenbaum et al. 2006). Studies of both human cocaine and alcohol addicts have found dysfunctional decision making in tasks involving delaying reward for more value and reversal learning tasks that probe cognitive flexibility and frontal lobe function (Bechara et al. 2002). The persistence of addiction, a chronic relapsing disorder, compares with the persistence in innate immune gene induction (Qin et al. 2007; Qin et al. 2008) and loss of behavioral flexibility.

\section{Adolescence, a key period of risk for frontal cortical damage}

Adolescence is an important developmental period when drug experimentation increases and behavioral control mechanisms mature. The frontal cortex develops during adolescence in parallel with the development of behavioral control (Ernst et al. 2009). The adolescent frontal cortex is uniquely sensitive to binge drinking neurotoxicity (Crews et al. 2000) and adolescent hippocampus uniquely sensitive to alcohol inhibition hippocampal of neurogenesis (Crews et al. 2006). Loss of frontal cortical function causes perseveration and repetition of previously learned behaviors due to failure to associate new information, e.g. negative consequences, into decision making. Models of adolescent binge drinking result in persistent reversal learning deficits (Coleman 2010) and persistent increases in proinflammatory innate immune gene expression and markers of neurodegeneration (Pascual et al. 2007). Anti-infammatory drugs protect against adolescent binge drinking brain damage models (Pascual et al. 2007) Initiation of drug experimentation during adolescence when frontal cortical behavioral control circuitry is developing increases vulnerability for life-long addiction (Crews et al. 2007). These studies suggest antiinflammatory therapies may have value in reducing drug induced changes in neurobiology that contribute to addiction.

\section{Summary}

The neurobiology of addiction develops over a course of repeated drug abuse and/or stress. Changes in neurobiology underline altered mood and cognition related to increased limbic negative affect and loss of frontal cortical behavioral control. Drug abuse, stress and other factors increase NF- $\mathrm{kB}$ transcription of multiple proinflammatory genes that spread across brain cell types further amplifying of NF- $\mathrm{kB}$ transcription through loops involving 
cytokines, chemokines, oxidases and proteases. Evidence supports the spread and persistence of brain innate immune gene induction as creating the neurobiology of addiction. Human studies of genetic risk for alcoholism and post-mortem brain support the role of innate immune genes in addiction. Animal behavior studies indicate increasing drug consumption and mounting negative affect and depression-like behavior are due to innate immune gene induction. Further, frontal cortical hyperexcitability, behavioral flexibility and loss of behavioral control can all be linked to innate immune genes. Together these finding suggest the neurobiology of addiction is due to innate immune gene altered signaling inducing the behaviors that define addiction. Therapies that blunt brain innate immune gene induction may represent new and novel approaches to preventing and/or reversing addiction.

\section{Acknowledgments}

The Authors wish to acknowledge Diana Lotito for help with the preparation of the manuscript as well as support from the Bowles Center for Alcohol Studies, School of Medicine University of North Carolina and the National Institutes of Health, National Institute on Alcoholism and Alcohol Abuse, AA020023, AA020024, AA020022, AA019767, AA11605.

\section{Bibliography}

Alfonso-Loechs S, Pascual-Lucas M, Blanco AM, Sanchez-Vera I, Guerri C. Pivotal role of TLR4 receptors in alcohol-induced neuroinflammtion and brain damage. J Neurosci. 2010; 30(24):82858295. [PubMed: 20554880]

Armario A. Activation of the hypothalamc-pituityary-adrenal axis by addictive drugs: different pathways, common outcome. Trends in Pharmacological Sciences. 2010; 31(7):318-325. [PubMed: 20537734]

Bechara A, Dolan S, Hindes A. Decision-making and addiction (part II): myopia for the future or hypersensitivity to reward? Neuropsyhologia. 2002; 40(10):1690-1705.

Blednov Y, Benavidez Jillian M, Perra Simona, Morikawa Hitoshi, Harris Adron R. Activation of neuroinflamatory Signaling by Lipopolysaccharide Produces a Prolonged increase of Voluntary Alcohol Intake in Mice. Brain, Behavior, and Immunity. 2011 in press.

Blednov YA, Bergeson SE, Walker D, Ferreira VM, Kuziel WA, Harris RA. Perturbation of chemkine networks by gene deletion alters the reinforcing actions of ethanol. Behav Brain Res. 2005; 165(1): 110-125. [PubMed: 16105698]

Blednov YA, Ponomarev I, Geil C, Bergeson S, Koob GF, Harris RA. Neuroimmune regulation of alcohol consumption: Behavioral validation of genes obtained from genomic studiesl. Addict Biol. $2010 \mathrm{~b}$ in press.

Breese GR, Knapp DJ, Overstreet DH, Navarro M, Wills TA, Angel RA. Repeated lipopolysaccharide (LPS) or cytokine treatments sensitize ethanol withdrawal-induced anxiety-like behavior. Neuropsychopharmacology. 2008; 33(4):867-876. [PubMed: 17551540]

Breese GR, Overstreet DH, Knapp DJ. Conceptual framework for the etiology of alcoholism: a "kindling”/stress hypothesis. Psychopharmacology (Berl). 2005; 178(4):367-380. [PubMed: 15765253]

Calu DJ, Roesch MR, Stalnaker TA, Schoenbaum G. Associative encoding in posterior piriform cortex during odor discrimination and reversal learning. Cereb Cortex. 2007; 17(6):1342-1349. [PubMed: 16882682]

Cao Q, Mak KM, Lieber CS. Cytochrome P4502E1 primes macrophages to increase TNF-alpha production in response to lipopolysaccharide. Am J Physiol Gastrointest Liver Physiol. 289(1):G95-107. [PubMed: 15961886]

Christoffel DJ, Golden SA, Dumitriu D, Robison AJ, Janssen WG, Ahn HF, Krishnan V, Reyes CM, Han MH, Ables JL, Eisch AJ, Dietz DM, Ferguson D, Neve RL, Greengard P, Kim Y, Morrison JH, Russo aSJ. lkB Kinase Regulates Social Defeat Stress-Induced Synaptic and Beheioral Plasticity. The Journal of Neuroscience. 2011; 31(1):314-321. [PubMed: 21209217] 
Chvatal A, Anderova M, Hock M, Prajerova I, Neprasova H, Chvatal V, Kirchhoff F, Sykova E. Three-dimensional confocal morphometry reveals structural changes in astrocytemorphology in situ. J Neurosci Res. 2007; 85(2):260-271. [PubMed: 17086549]

Coleman L, Jun H, Joohwi L, Styner M, Crews FT. Adolescent Binge Drinking Alters Adult Brain Neurotransmitter Gene Expression, Behavior, Brain Regional Volumes, and Neurochemistry in mice. Alcoholism: Clinical and Experimental Research. 2010; 35(4)

Colton CA, Wilcock DM. Assessing activation states in microglia. CNS Neurol Disord Drug Targets. 2010; 9(2):174-191. [PubMed: 20205642]

Crews F, He J, Hodge C. Adolescent cortical development: a critical period of vulnerability for addiction. Pharmacol Biochem Behav. 2007; 86(2):189-199. [PubMed: 17222895]

Crews F, Nixon K, Kim D, Joseph J, Shukitt-Hale B, Qin L, Zou J. BHT blocks NF-kappaB activation and ethanol-induced brain damage. Alcohol Clin Exp Res. 2006; 30(11):1938-1949. [PubMed: 17067360]

Crews FT, Bechara R, Brown LA, Guidot DM, Mandrekar P, Oak S, Qin L, Szabo G, Wheeler M, Zou J. Cytokines and alcohol. Alcohol Clin Exp Res. 2006; 30(4):720-730. [PubMed: 16573591]

Crews FT, Braun CJ, Hoplight B, Switzer RC 3rd, Knapp DJ. Binge ethanol consumption causes differential brain damage in young adolescent rats compared with adult rats. Alcohol Clin Exp Res. 2000; 24(11):1712-1723. [PubMed: 11104119]

Crews FT, Mdzinarishvili A, Kim D, He J, Nixon K. Neurogenesis in adolescent brain is potently inhibited by ethanol. Neuroscience. 2006; 137(2):437-445. [PubMed: 16289890]

Crews FT, Nixon K. Alcohol, neural stem cells, and adult neurogenesis. Alcohol Res Health. 2003; 27(2):197-204. [PubMed: 15303631]

Crews FT, Nixon K. Mechanisms of neurodegeneration and regeneration in alcoholism. Alcohol Alcohol. 2009; 44(2):115-127. [PubMed: 18940959]

Dranovsky A, Hen R. Hippocampal neurogenesis: regulation by stress and antidepressants. Biol Psychiatry. 2006; 59(12):1136-1143. [PubMed: 16797263]

Eisenberger NI, Berkman ET, Inagaki TK, Rameson LT, Mashal NM, Irwin MR. Inflammationinduced anhedonia: endotoxin reduces ventral striatum responses to reward. Biol Psychiatry. 2010; 68(8):748-754. [PubMed: 20719303]

Ernst M, Romeo RD, Andersen SL. Neurobiology of the development of motivated behaviors in adolescence: a window into a neural systems model. Pharmacol Biochem Behav. 2009; 93(3):199_ 211. [PubMed: 19136024]

Flatscher-Bader T, van der Brug M, Hwang JW, Gochee PA, Matsumoto I, Niwa S, Wilce PA. Alcohol-responsive genes in the frontal cortex and nucleus accumbens of human alcoholics. J Neurochem. 2005; 93(2):359-370. [PubMed: 15816859]

Garg AD, Nowis D, Golab J, Vandenabeele P, Krysko DV, Agostinis P. Immunogenic cell death, DAMPs and anticancer therapeutics: an emerging amalgamation. Biochim Biophvs Acta. 2010; 1805(1):53-71.

Gerald Frank M, Maier Steven F, Watkins Linda R. Stress- and Glucocorticoid-lnduced Priming of Neuroinflammatory Responses: Potential echanisms of Stress-Induced Vulnerability to Drugs of Abuse. Brain, Behavior, and Immunity. 2011 in press.

Ghosh S, Hayden MS. New regulators of NF-kappaB in inflammation. Nat Rev Immunol. 2008; 8(11): 837-848. [PubMed: 18927578]

Gilson AM. The concept of addiction in law and regulatory policy related to pain management: a critical review. Clin J Pain. 2010; 26(1):70-77. [PubMed: 20026957]

Gomez-Pinedo U, Felez MC, Sancho-Bielsa FJ, Vidueira S, Cabanes C, Soriano M, Garcia-Verdugo JM, Barcia JA. Improved technique for stereotactic placement of nerve grafts between two locations inside the rat brain. J Neurosci Methods. 2008; 174(2):194-201. [PubMed: 18692091]

Graeber MB. Changing face of microglia. Science. 2010; 330(6005):783-788. [PubMed: 21051630]

Greenfield SF, Weiss RD, Muenz LR, Vagge LM, Kelly JF, Bello LR, Michael J. The effect of depression on return to drinking: a prospective study. Arch Gen Psychiatry. 1998; 55(3):259-265. [PubMed: 9510220]

Greer JM, Capecchi MR. Hoxb8 is required for normal grooming behavior in mice. Neuron. 2002; 33(1):23-34. [PubMed: 11779477] 
Gregus A, Wintink AJ, Davis AC, Kalynchuk LE. Effect of repeated corticosterone injections and restraint stress on anxiety and depression-like behavior in male rats. Behav Brain Res. 2005; 156(1):105-114. [PubMed: 15474655]

Gruber AJ, Calhoun Gwendolyn G, Shusterman lgor, Schoenbaum Geoffrey, Roesch Matthew R, O'Donnell Patricio. More Is Less: A Disinhibited Prefrontal Cortex Impairs Cognitive Flexibility. The Journal of Neuroscience. 2010; 30(50):17102-17110. [PubMed: 21159980]

He J, Crews FT. Increased MCP-1 and microglia in various regions of the human alcoholic brain. Exp Neurol. 2008; 210(2):349-358. [PubMed: 18190912]

Hingson RW, Zha W, Weitzman ER. Magnitude of and trends in alcohol-related mortality and morbidity among U.S. college students ages 18-24, 1998-2005. J Stud Alcohol Drugs suppl. 2009; (16):12-20. [PubMed: 19538908]

Huang W, Tang Y, Li L. HMGB1, a potent proinflammatory cytokine in sepsis. Cytokine. 2010; 51(2):119-126. [PubMed: 20347329]

Hutchinson MR, Wu Yue, Lousberg Erin L, Moldenhauer Lachlan M, Hayball John D, Robertson Sarah A, Coller Janet K, Watkings Linda R, Somogyi Andrew A. Attenuation of microglial and IL-1 signaling protects mice from acute alcohol-induced sedation and/or motor impairment. Brain, Behavior, and Immunity. 2011 in press.

Jentsch JD, Taylor JR. Impulsivity resulting from frontostriatal dysfunction drug abuse: implications for the control of behavior by reward-related stimuli. Psychopharmacology (Berl). 1999; 146(4): 373-390. [PubMed: 10550488]

Johnson SA, Fournier NM, Kalynchuk LE. Effect of different doses of corticosterone on depressionlike behavior and HPA axis responses to a novel stressor. Behav Brain Res. 2006; 168(2):280 288. [PubMed: 16386319]

Kalivas PW, O'Brien C. Drug addiction as a pathology of staged neuroplasticity. Neuropsychopharmacology. 2008; 33(1):166-180. [PubMed: 17805308]

Kelley KW, Dantzer Robert. Alcoholism and Inflammation: Neuroimmunology of Behavioral and Mood Disorders. Brain Behavior, and Immunity. 2011 in print.

Knapp DJ, Crews FT. Induction of cyclooxygenase-2 in brain during acute and chronic ethanol treatment and ethanol withdrawal. Alcohol Clin Exp Res. 1999; 23(4):633-643. [PubMed: 10235299]

Koo JW, Duman RS. IL-1beta is an essential mediator of the antineurogenic and anhedonic effects of stress. Proc Natl Acad Sci U S A. 2008; 105(2):751-756. [PubMed: 18178625]

Koo JW, Russo SJ, Ferguson D, Nestler EJ, Duman RS. Nuclear factor-kappaB is a critical mediator of stress-impaired neurogenesis and depressive behavior. Proc Natl Acad Sci U S A. 2011; 107(6): 2669-2674. [PubMed: 20133768]

Koob GF, Volkow ND. Nerurocircuityy of addiction. Neuropsychopharmacology. 2010; 35(1):217238. [PubMed: 19710631]

Li TK. Quantifying the risk for alcohol-use and alcohol-attributable health disorders: present findings and future research needs. J Gastroenterol Hepatol. 2008; 23(1):S2-8. [PubMed: 18336658]

Liu B, Du L, Hong JS. Naloxone protects rat dopaminergic neurons against inflammatory damage through inhibition of microglia activation and superoxide generation. J Pharmacol Exp Ther. 2000; 293(2):607-617. [PubMed: 10773035]

Liu B, Jiang JW, Wilson BC, Du L, Yang SN, Wang JY, Wu GC, Cao XD, Hong JS. Systemic infusion of naloxone reduces degeneration of rat substantia nigral dopaminergic neurons induced by intranigral injection of lipopolysaccharide. J Pharmacol Exp Ther. 2000; 295(1):125-132. [PubMed: 10991969]

Liu J, Lewohl JM, Harris RA, Iyer VR, Dodd PR, Randall PK, Mayfield RD. Patterns of gene expression in the frontal cortex discriminate alcoholic from nonalcoholic individuals. Neuropsychopharmacology. 2006; 31(7):1574-1582. [PubMed: 16292326]

Liu L, Belkadi A, Darnall L, Hu T, Drescher C, Cotleur AC, Padovani-Claudio D, He T, Choi K, Lane TE, Miller RH, Ransohoff RM. CXCR2-positive neutrophils are essential for cuprizone-induced demyelination: relevance to multiple sclerosis. Nat Neurosci. 13(3):319-326. [PubMed: 20154684] 
Loftis JM, Choi D, Hoffman W, Huckans MS. Methamphetamine Causes Persistent Immune Dysregulation: A Cross-Species, Translational Report. Neurotox Res. 2010

Madrigal B, Puebla P, Caballero E, Pelaez R, Gravalos DG, Medarde M. Synthesis of imidaz[4,5d] oxazolo[3,4-a[pyridines. New heterocyclic analogues of lignans. Arch Pharm (Weinheim). 2001; 334(5):177-179. [PubMed: 11413825]

Madrigal JL, Garcia-Bueno B, Moro MA, Lizasoain I, Lorenzo P, Leza JC. Relationship between cyclooxygenase-2 and nitric oxide synthase-2 in rat cortex after stress. Eur J Neurosci. 2003; 18(6):1701-1705. [PubMed: 14511348]

Madrigal JL, Moro MA, Lizasoain I, Lorenzo P, Leza JC. Stress-induced increase inextracellular sucrose space in rats is mediated by nitric oxide. Brain Res. 2002; 938(1-2):87-91. [PubMed: 12031539]

Malberg JE, Duman RS. Cell proliferation in adult hippocampus is decreased by inescapable stress: reversal by fluoxetine treatment. Neuropsychopharmacology. 2003; 28(9):1562-1571. [PubMed: 12838272]

Mao SR, MoerMan-Herzog AM, Chen Y, Barger SW. Unique aspects of transcriptional regulation in neurons--nuances in NFkappaB and Sp1-reLated factors. J Neuroinflammation. 2009; 6:16. [PubMed: 19450264]

Maroso M, Balosso S, Ravizza T, Liu J, Aronica E, lyer AM, Rossetti C, Molteni M, Casalgrandi M, Manfredi AA, Bianchi ME, Vezzani A. Toll-like receptor 4 and high-mobility group box-1 are involved in ictogenesis and can be targeted to reduce seizures. Nat Med. 2010; 16(4):413-419. [PubMed: 20348922]

Massa PT, Aleyasin H, Park DS, Mao X, Barger SW. NFkappaB in neurons? The uncertainty principle in neurobiology. J Neurochem. 2006; 97(3):607-618. [PubMed: 16573643]

Mendelson JH, Babor TF, Melloo NK, Pratt H. Alcoholism and prevalence of medical and psychiatric disorders. J Stud Alcohol. 1986; 47(5):361-366. [PubMed: 3762158]

Miller NS, Klamen D, Hoffmann NG, Flaherty JA. Prevalence of depression and alcohol and other drug dependence in addictions treatment populations. J Psychoactive Drugs. 1996; 28(2):111-124. [PubMed: 8811580]

Mueller TI, Lavori PW, Keller MB, Swartz A, Warshaw M, Hasin D, Coryell W, Endicott J, Rice J, Akiskal H. Prognostic effect of the variable course of alcoholism on the 10-year course of depression. Am J Psychiatry. 1994; 151(5):701-706. [PubMed: 8166311]

Mulligan MK, Ponomarev I, Hitzemann RJ, Belknap JK, Tabakoff B, Harris RA, Crabbe JC, Blednov YA, Grahame NJ, Phillips TJ, Finn DA, Hoffman PL, Iyer VR, Koob GF, Bergeson SE. Toward understanding the genetics of alcohol drinking through transcriptom meta-analysis. Proc Natl Acad Sci U S A. 2006; 103(16):6368-6373. [PubMed: 16618939]

Munhoz CD, Sorrells SF, Caso JR, Scavone C, Sapolsky RM. Glucocorticoids exacerbate lipopolysaccharide-induced signaling in the frontal cortex and hippocampus in a dose-dependent manner. J Neurosci. 2010; 30(41):13690-13698. [PubMed: 20943909]

O'Brien CP. Review. Evidence-based treatments of addiction. Philos Trans R Soc Lond B Biol Sci. 2008; 363(1507):3277-3286. [PubMed: 18640914]

Obernier JA, White AM, Swartzwelder HS, Crews FT. Cognitive deficits and CNS damage after a 4day binge ethanol exposure in rats. Pharmacol Biochem Behav. 2002; 72(3):521-532. [PubMed: 12175448]

Okvist A, Johansson S, Kuzmin A, Bazov I, Merino-artinez R, Ponomarev I, Mayfield RD, Harris RA, Sheedy D, Garrick T, Harper C, Hurd YL, Terenius L, Ekstrom TJ, Bakalkin G, Yakovleva T. Neuroadaptations in human chronic alcoholics: dysregulation of the NF-kappaB system. PLoS One. 2007; 2(9):e930. [PubMed: 17895971]

Pahl HL. Activators and target genes of Rel/NF-kappaB transcription factors. Oncogene. 1999; 18(49): 6853-6866. [PubMed: 10602461]

Pascual M, Blanco AM, Cauli O, Minarro J, Guerri C. Intermittent ethanol exposure induces inflammatory brain damage and causes long-term behavioural alterations in adolescent rats. Eur $\mathrm{J}$ Neurosci. 2007; 25(2):541-550. [PubMed: 17284196] 
Pastor IJ, Laso FJ, Avila JJ, Rodriguez RE, Gonzalez-Sarmiento R. Polymorphism in the interleukin-1 receptor antagonist gene is associated with alcoholism in Spanish men. Alcohol Clin Exp Res. 2000; 24(10):1479-1482. [PubMed: 11045853]

Pastor IJ, Laso FJ, Romero A, Gonzalez-Sarmiento R. Interleukin-1 gene cluster polymorphisms and alcoholism in Spanish men. Alcohol Alcohol. 2005; 40(3):181-186. [PubMed: 15797878]

Powell EE, Edwards-Smith CJ, Hay JL, Clouston AD, Crawford DH, Shorthouse C, Purdie DM, Jonsson JR. Host genetic factors influence disease progression in chronic hepatitis C. Hepatology. 2000; 31(4):828-833. [PubMed: 10733535]

Qin L, Block ML, Liu Y, Bienstock RJ, Pei Z, Zhang W, Wu X, Wilson B, Burka T, Hong JS. Microglial NADPH oxidase is a novel target for femtomolar neuroprotection against oxidative stress. FASEB J. 2005; 19(6):550-557. [PubMed: 15791005]

Qin L, He J, Hanes RN, Pluzarev O, Hong JS, Crews FT. Increased systemic and brain cytokine production and neuroinflamtion by endotoxin following ethanol treatment. Neuroinflammation. 2008; 5:10.

Qin L, Wu X, Block ML, Liu Y, Breese GR, Hong JS, Knapp DJ, Crews FT. Systemic LPS causes chronic neuroinflammation and progressive neurodegeneration. Glia. 2007; 55(5):453-462. [PubMed: 17203472]

Raison CL, Borisov AS, Majer M, Drake DF, Pagnoni G, Woolwine BJ, Vogt GJ, Massung B, Miller AH. Activation of central nervous system inflammatory pathways by interferon-alpha: relationship to monoamines and depression. Biol Psychiatry. 2009; 65(4):296-303. [PubMed: 18801471]

Ransohoff RM, Cardona AE. The myeloid cells of the central nervous system parenchyma. Nature. 2010; 468(7321):253-262. [PubMed: 21068834]

Reissner KJ, Kalivas PW. Using glutamate homeostasis as a target for treating addictive disorders. Behav Pharmacol. 2010; 21(5-6):514-522. [PubMed: 20634691]

Ries RK MD, Miller SC MD FASAM FAPA CMRO, Fiellin DA MD, Saltz R MD MPH, FACP, FASAM. principles of Addiction Medicine. American Society of Addiction Medicine. 2009

Robinson TE, Berridge KC. Addiction. Annu Rev Psychol. 2003; 54:25-53. [PubMed: 12185211]

Russo SJ, Mazei-Robison MS, Ables JL, Nestler EJ. Neurotrophic factors and structural plasticity in addiction. Neuropharmacology. 2009; 56(1):73-82. [PubMed: 18647613]

Saiz PA, Garcia-Portilla MP, Florez G, Corcoran P, Arango C, Morales B, Leza JC, Alvarez S, Diaz EM, Alvarez V, Coto E, Nogueiras L, Bobes J. Polymorphisms of the lL-1 gene complex are associated with alcohol dependence in Spanish Caucasians: data from an association study. Alcohol Clin Exp Res. 2009; 33(12):2147-2153. [PubMed: 19764937]

Santarelli L, Saxe M, Gross C, Surget A, Battaglia F, Dualwa S, Weisstaub N, Lee J, Duman R, Arancio O, Belzung C, Hen R. Requirement of hippocamal neurogenesis for hebehavioral effects of antidepressants. Science. 2003; 301(5634):805-809. [PubMed: 12907793]

Schoenbaum G, Roesch MR, Stalnaker TA. Orbitofrontal cortex, decision-making and drug addiction. Trends Neurosci. 2006; 29(2):116-124. [PubMed: 16406092]

Schoenbaum G, Saddoris MP, Ramus SJ, Shaham Y, Setlow B. Cocaine-experienced rats exhibit learning deficits in a task sensitive to orbitofrontal cortex lesions. Eur J Neurosci. 2004; 19(7): 1997-2002. [PubMed: 15078575]

Schoenbaum G, Shaham Y. The role of orbitofrontal cortex in drug addiction: a review of preclinical studies. Biol Psychiatry. 2008; 63(3):256-262. [PubMed: 17719014]

Schuckit MA. An overview of genetic influences in alcoholism. J Subst Abuse Treat. 2009; 36(1):S514. [PubMed: 19062348]

Schuckit MA, Tipp JE, Bucholz KK, Nurnberger JI Jr, Hesselbrock VM, Crowe RR, Kramer J. The life-time rates of three major mood disorders and four major anxiety disorders in alcoholics and controls. Addiction. 1997; 92(10):1289-1304. [PubMed: 9489046]

Shpargel KB, Jalabi BW, Jin Y, Dadabayev A, Penn MS, Trapp BD. Preconditioning paradigms and pathways in the brain. Clve Clin J Med. 2008; 75(2):S77-82.

Stalnaker TA, Takahashi Y, Roesch MR, Schoenbaum G. Neural substrates of cognitive inflexibility after chronic cocaine exposure. Neuropharmacology. 2009; 56(1):63-72. [PubMed: 18692512] 
Stevenson JR, Schroeder JP, Nixon K, Besheer J, Crews FT, Hodge CW. Abstinence following alcohol drinking produces depression-like behavior and reduced hippocamal neurogenesis in mice. Neuropsyhopharmcology. 2009; 4(5):1209-1222.

Tanapat P, Hastings NB, Rydel TA, Galea LA, Gould E. Exposure to fox odor inhibits cell proliferation in the hippocampus of adult rats via an adrenal hormone-dependent mechanism. $\mathrm{J}$ Comp Neurol. 2001; 437(4):496-504. [PubMed: 11503148]

Taylor MW, Tsukahara T, McClintick JN, Edenberg HJ, Kwo P. Cyclic changes in gene expression induced by Peg-interferon alfa-2b plus ribavirin in peripheral blood monocytes (PBMC) of hepatitis C patients during the first 10 weeks of treatment. J Transl Med. 2008; 6:66. [PubMed: 18986530]

Videbech P, Ravnkilde B. Hippocampal volume and depression: a meta-analysis of MRI studies. Am J Psychiatry. 2004; 161(11):1957-1966. [PubMed: 15514393]

Volkow ND, Baler RD, Goldstein RZ. Addiction: pulling at the neural threads of social behaviors. Neuron. 2011; 69(4):599-602. [PubMed: 21338873]

Ward RJ, Colivicchi MA, Allen R, Schol F, Lallemand F, de Witte P, Ballini C, Corte LD, Dexter D. Neuro-inflammation induced in the hippocampus of 'binge drinking' rats may be mediated by elevated extracellular glutamate content. J Neurochem. 2009; 111(5):1119-1128. [PubMed: 19765190]

Ward RJ, Zhang Y, Crichton RR, Piret B, Piette J, de Witte P. Identification of the nuclear transcription factor NFkappaB in rat after in vivo ethanol administration. FEBS Lett. 1996; 389(2): 119-122. [PubMed: 8766812]

Webb A, Lind PA, Kalmijn J, Feiler HS, Smith TL, Schuckit MA, Wilhelmsen K. The investigation into CYP2E1 in relation to the level of response to alcohol through a combination of linkage and association analysis. Alcohol Clin Exp Res. 2010; 35(1):10-18. [PubMed: 20958328]

Wilhelmsson U, Bushong EA, Price DL, Smarr BL, Phung V, Terada M, Ellisman MH, Penkny M. Redefining the concept of reactive astrocytes as cells that remain within their unique domains upon reaction to injury. Proc Natl Acad Sci U S A. 2006; 103(46):17513-17518. [PubMed: 17090684]

Yang L, Seifert A, Wu D, Wang X, Rankovic V, Schroder H, Brandenburg LO, Hollt V, Koch T. Role of phospholipase D2/phosphatidic acid signal transduction in micro- and delta- opioid receptor endocytosis. Mol Pharmacol. 2010; 78(1):105-113. [PubMed: 20354103]

Zou J, Crews F. CREB and NF-kappaB transcription factors regulate sensitivity to excitotoxic and oxidative stress induced neuronal cell death. Cell Mol Neurobiol. 2006; 26(4-6):385-405. [PubMed: 16633891]

Zou J, Crews F. Induction of innate immune gene expression cascades in brain slice cultures by ethanol: key role of NF-kappaB and proinflammatory cytokines. Alcohol Clin Exp Res. 2010; 34(5):777-789. [PubMed: 20201932]

Zou JY, Crews FT. TNF alpha potentiates glutamate neurotoxicity by inhibiting glutamate uptake in organotypic brain slice cultures: neuroprotection by NF kappa B inhibition. Brain Res. 2005; 1034(1-2):11-24. [PubMed: 15713255]

\section{Abbreviations}

$\begin{array}{ll}\text { AP1 } & \text { Activator protein 1 } \\ \text { CYP2E1 } & \text { Cytochrome P450 2E1 } \\ \text { DAMPs } & \text { Damage-associated molecular pattern } \\ \text { ECM } & \text { Extra cellular matix } \\ \text { EtOH } & \text { Ethanol } \\ \text { HMGB1 } & \text { high mobility group box 1 } \\ \text { IL-1 } \beta & \text { Interleukin-1 beta }\end{array}$


IL1 Interleukin-1

LPS lipopolysaccharide

MMP Matrix Metalloproteinase

MCP-1 Monocyte chemoattractant protein-1

NOX Nicotinamide adenine dinucleotide phosphate (NADPH) oxidases

gp91 NADPH oxidase flavocytochrome b components

NF- $x$ B Nuclear factor kappa-light-chain-enhancer of activated B cells

TLR Toll-Like receptor

TNFa Tissue necrosis factor-alpha

TACE TNFa converting enzyme

tPA Tissue Plasminogen Activator 


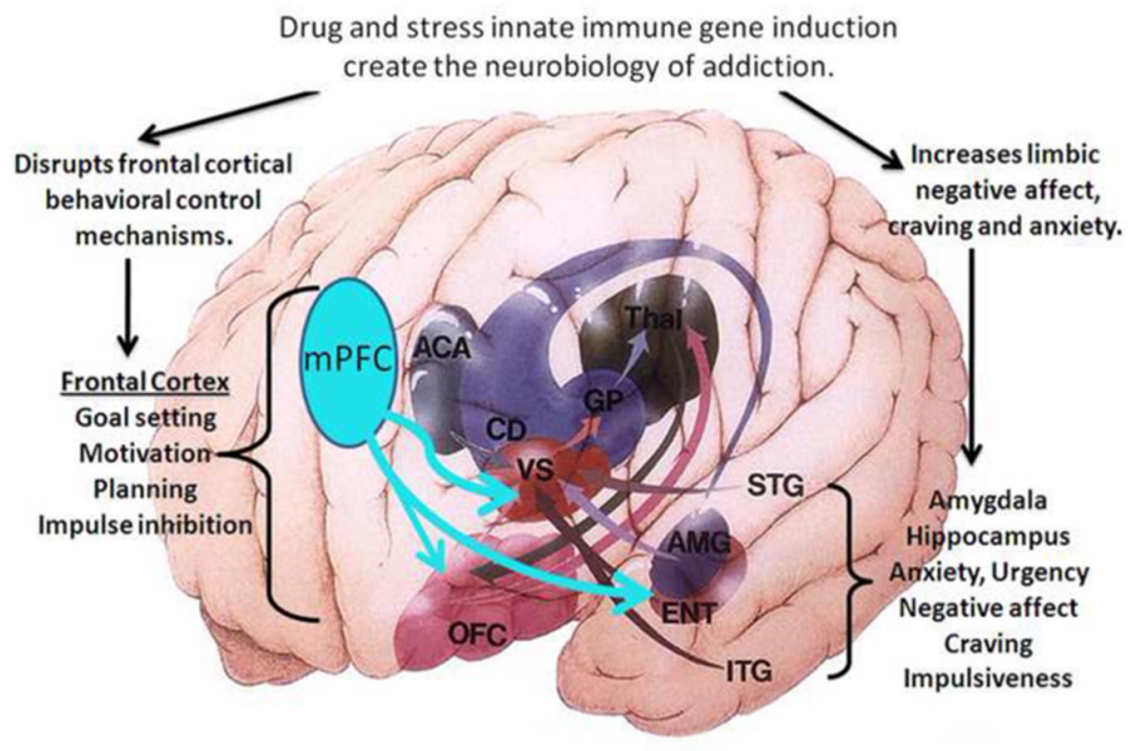

Figure 1. Neuroanatomical components of the neurobiology of addiction

A simplified schematic diagram of the human brain frontal-cortical and limbic circuitry that contribute to addiction. Shown are internal structures highlighted with projections indicated by arrows with the structure color. Frontal cortical brain regions select attention, monitor the environment and planning by assessing information and predicting outcomes (Schoenbaum et al. 2006; Schoenbaum and Shaham 2008). Limbic regions including the amygdala (AMG) and entorhinal cortex (ENT) also project to VS, from the temporal lobe. The harmful behaviors of severe alcohol, opiate and stimulant drug dependence involve changes in frontal lobes leading to loss of attention, poor decision making, and decreased cognitive flexibility as well as increased temporal lobe anxiety-negative affect urgency that promote the progressive loss of behavioral control over drug use. Frontal cortex regulation of limbic structures and communication with sensory thalamic input is glutamatergic. Glutamatergic hyperexcitability, due to disrupted innate immune gene induction (Zou and Crews 2005; Crews et al. 2006), inactivates frontal cortical responses (Gruber 2010). Temporal lobe limbic signaling involves GABAergic and peptidergic projection neurons that show increased bad feelings due to activation of innate immune genes in hippocampus and amygdale and loss of frontal cortical control increasing urgency-negative affect. Thus, innate immune gene induction in frontal and temporal lobes of brain disrupt neurocircuitry and signaling consistent with addiction. 


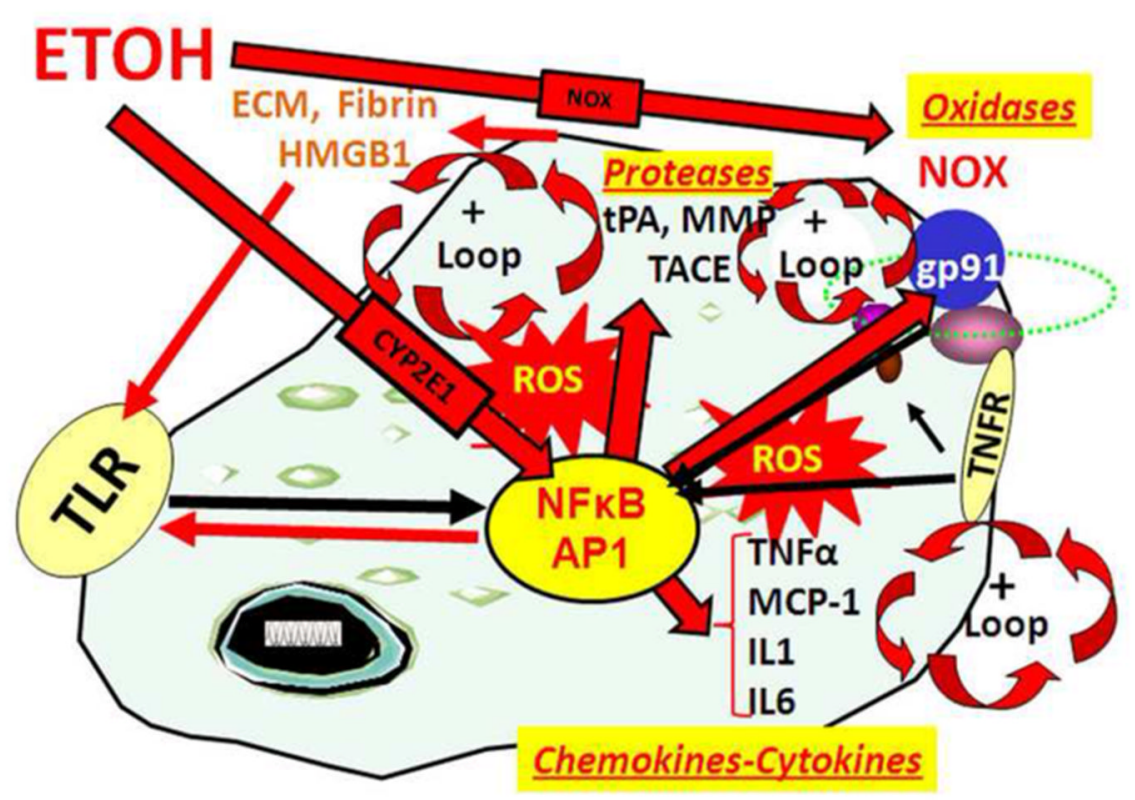

Figure 2. Loops of NF- $x$ B (nuclear factor kappa-light-chain-enhancer of activated B cells) activation of transcription increases chemokines-cytokines, oxidases and proteases

$\mathrm{NF}-\mathrm{\kappa B}$ is a key transcription factor involved in induction of innate immune genes (Ghosh and Hayden 2008). Stimuli such as stress, drugs, peptides chemokines, cytokines, reactive oxygen species, ultraviolet irradiation, bacteria, viruses, trauma and other factors increase NF- $\kappa$ B-DNA binding and transcription (Fig. 2). Reactive oxygen species (ROS) from oxidases such as NADPH-oxidase (NOX) or ethanol metabolism by Cyp2E1 increase NF$\kappa \mathrm{B}$ transcription of NOX2 $2^{\text {phox }}$ (gp91) a key NOX catalytic subunit (Cao et al. 2005) that produces ROS (Qin et al. 2008). Cytokines and chemokines, such as TNFa, IL1 $\beta$, IL6 and MCP-1, as well as their receptors (TNFR in figure) are induced creating another amplification loop. Toll Like-Receptors (TLR) are increased by ethanol (Alfonso-Loeches et al. 2010) as are other damage-associated molecular pattern (DAMP) receptors and there agonists creating positive activation loops (Garg et al. 2010). TLR and HMGB1 create another activation-amplification loop. Persistent and repeated activation occurs through positive cycles of activation (+ loops). These loops spread innate immune signaling through paracrine and autocrine mechanisms across brain altering neurocircuitry and neurobiology. 

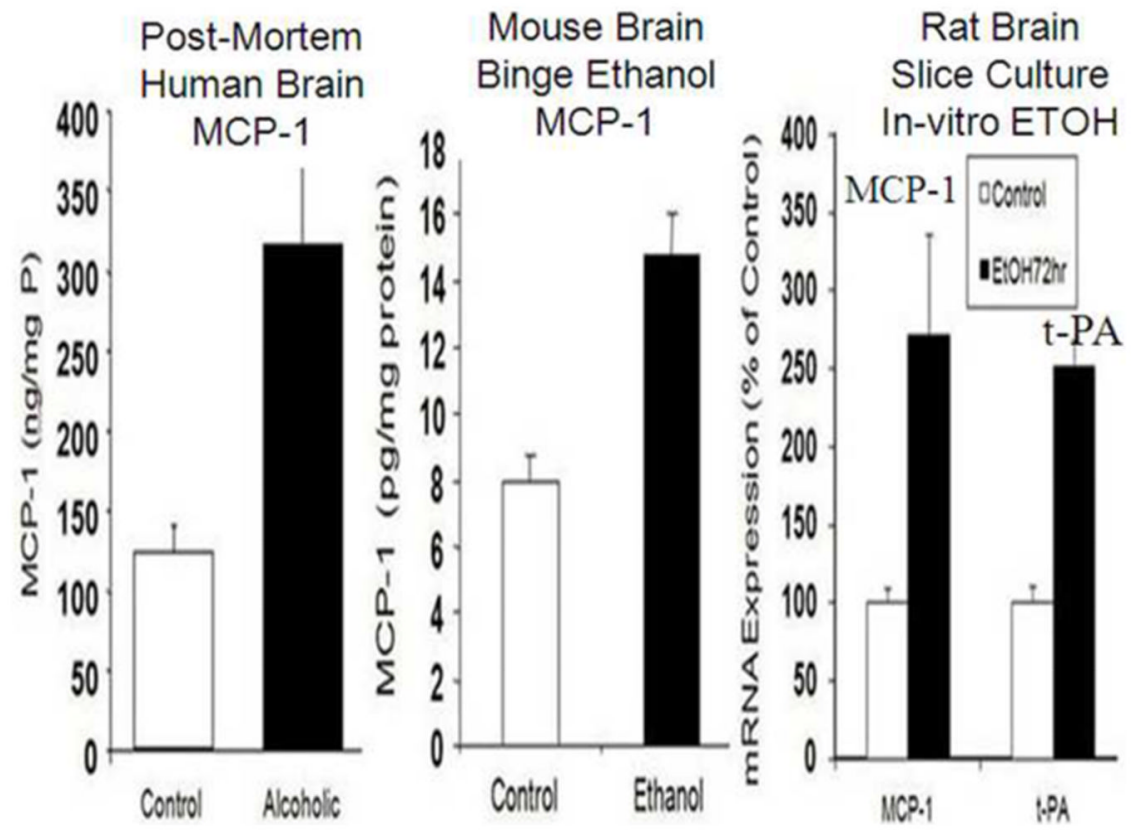

Figure 3. Increased CCL2 in post-mortem human alcoholic brain, chronic alcohol treated mouse brain and ethanol treatment of rat hippocampal-entorhinal cortex (HEC) brain slices cultures Left-MCP-1 protein levels from human brain homogenate contain increased MCP-1 in ventral tegmental area, substantia nigra, hippocampus and amygdala. (He and Crews 2008). Middle: Mouse Brain MCP-1 is increased by chronic ethanol treatment. Mice (C57B1/6) were treated with10 daily doses of ethanol (5 gm/kg. i.g., (Qin et al. 2008). Shown are brain levels of MCP-1 in mice 8 days after chronic ethanol treatment Right: Rat Hippocampal HEC brain-slice cultures treated with ethanol for 4 days. Shown are MCP-1 and tPA. (Zou and Crews 2010). These studies indicate ethanol induces the innate immune chemokine $\mathrm{MCP}-1$ in mouse and rat brain and suggest alcoholics induce MCP-1 through alcohol drinking. Elevated MCP-1 in post-mortem human alcoholic brain is consistent with ethanol activation of innate immune genes contributing to alcoholism. 


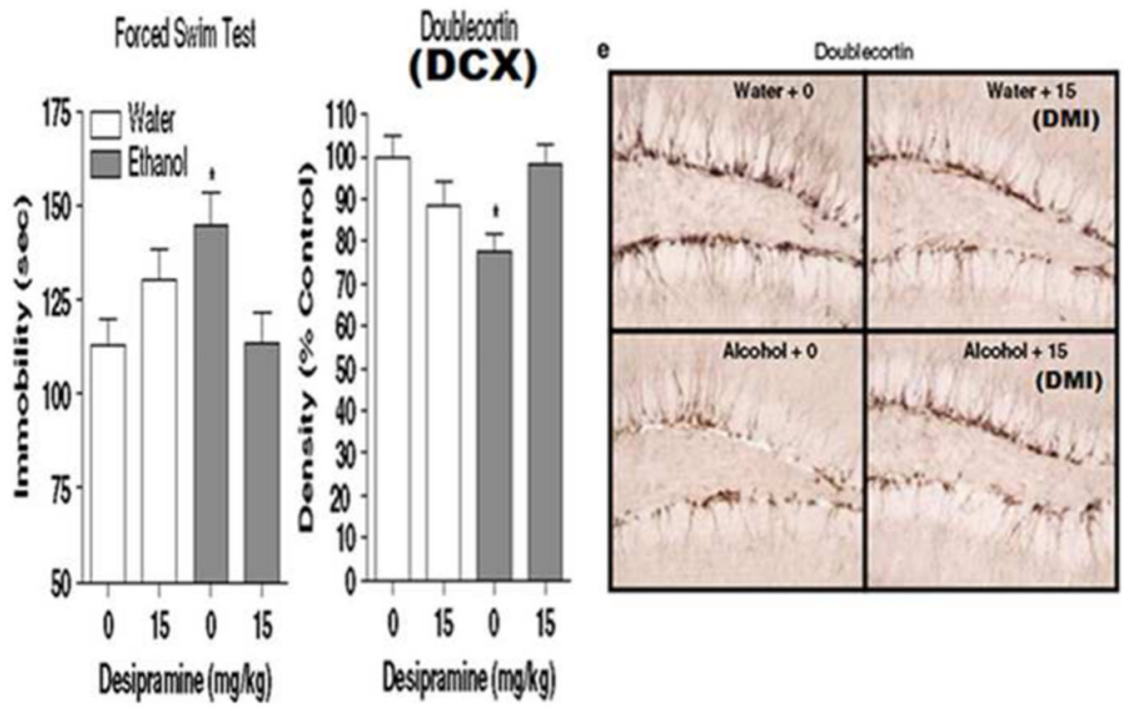

Figure 4. Chronic alcohol self-administration induces depression-like behavior and inhibits hippocampal neurogenesis: reversal by the antidepressant Desipramine C57BL/6J mice self-administered ethanol (10\% v/v) or water for 28 days. Forced Swim Test (FST) immobility is an index of depression-like behavior. The increase in FST immobility reflects chronic alcohol induced depression-negative affect. Treatment with the antidepressant, Desipramine, reverses depression-like behavior, e.g. decreases immobility. (Middle) Ethanol decreases doublecortin (DCX+IR), a marker of neurogenesis. Desipramine treatment reverses ethanol DCX-neurogenesis. (Right) Pictures of DCX stain in watercontrol animals and alcohol animals. These findings are consistent with drug induced negative affect reflected in loss of neurogenesis and depression-like behavior. This figure is adapted from Stevenson (Stevenson et al. 2009). 